\title{
A maternally inherited frameshift CDKL5 variant in a male with global developmental delay and late-onset generalized epilepsy \\ Dol:
}

10.1002/ajmg.a.40661

\section{Document Version}

Accepted author manuscript

Link to publication record in Manchester Research Explorer

Citation for published version (APA):

Deciphering Developmental Disorders Study (2019). A maternally inherited frameshift CDKL5 variant in a male with global developmental delay and late-onset generalized epilepsy. American Journal of Medical Genetics. Part A. https://doi.org/10.1002/ajmg.a.40661

Published in:

American Journal of Medical Genetics. Part A

\section{Citing this paper}

Please note that where the full-text provided on Manchester Research Explorer is the Author Accepted Manuscript or Proof version this may differ from the final Published version. If citing, it is advised that you check and use the publisher's definitive version.

\section{General rights}

Copyright and moral rights for the publications made accessible in the Research Explorer are retained by the authors and/or other copyright owners and it is a condition of accessing publications that users recognise and abide by the legal requirements associated with these rights.

\section{Takedown policy}

If you believe that this document breaches copyright please refer to the University of Manchester's Takedown Procedures [http://man.ac.uk/04Y6Bo] or contact uml.scholarlycommunications@manchester.ac.uk providing relevant details, so we can investigate your claim.

\section{OPEN ACCESS}




\section{and late-onset generalized epilepsy}

Harry Fraser* (1), Amy Goldman* (1), Ronnie Wright (1), The Deciphering Developmental Disorders study (2), Siddharth Banka $(1,3)$.

1. Manchester Centre for Genomic Medicine, St Mary's Hospital, Manchester University NHS Foundation Trust, Health Innovation Manchester, Manchester, UK.

2. The Wellcome Trust Sanger Institute, Cambridge, UK.

3. Division of Evolution \& Genomic Sciences, School of Biological Sciences, Faculty of Biology, Medicine and Health, University of Manchester, Manchester, UK.

*These authors contributed equally to this work.

\section{Correspondence}

Harry Fraser, Manchester Centre for Genomic Medicine, Saint Mary's Hospital, Oxford Road, Manchester. M13 9WL. U.K. Tel: +44 (0) 161276 6264; Fax: +44 (0) 161276 6145; harry.fraser@mft.nhs.uk 


\begin{abstract}
Pathogenic CDKL5 variants are associated with $\mathrm{X}$-linked dominant early infantile epileptic encephalopathy, characterized by an early-onset severe mixed seizure disorder in females. Pathogenic $C D K L 5$ variants are rare in males, with only approximately 20 male patients reported to date.

We present a maternally inherited frameshift CDKL5 c.2809_2810insA p.(Cys937Ter) variant in a 13-year-old male with intellectual disability and late-onset generalized epilepsy, expanding the known spectrum of $C D K L 5$-related disorder in males. Though the possibility of this variant not being causal cannot be completely excluded, several factors support its pathogenicity. Firstly, the proband's phenotype is consistent with $C D K L 5$-related disorder, although with a later seizure onset than usually described. Secondly, the variant segregation is consistent with an X-linked recessive inheritance pattern. Thirdly, this variant is expected to result in truncation of some CDKL5 transcripts, and is in a region where pathogenic variants have been previously described. Interestingly, the variant is located in exon 20 of $C D K L 5$, and is excluded from seven out of nine known CDKL5 transcripts, potentially accounting for the later seizure onset and the atypical inheritance pattern.
\end{abstract}

This novel CDKL5 variant adds to the variability of the documented phenotypic profile and to the debate around the role of C-terminus variants in CDKL5-related disease.

Key words: CDKL5, X-linked inheritance, intellectual difficulty, developmental delay, epilepsy. 


\section{INTRODUCTION}

The CDKL5 gene encodes the cyclin-dependant kinase-like 5 protein that mediates MeCP2 phosphorylation [Intusoma et al., 2011]. Pathogenic CDKL5 variants usually cause an X-linked dominant early infantile epileptic encephalopathy (OMIM 300672) which is characterized by an early-onset severe mixed seizure disorder in females, often with normal brain magnetic resonance imaging (MRI) findings [Tao et al., 2004; Weaving et al., 2004; Evans et al., 2005; Archer et al., 2006; Allou et al., 2017]. There is one reported case of a last-exon nonsense CDKL5 variant in a female with a late-onset seizure disorder [Psoni et al., 2010]. Other key features in affected females include severe developmental delay, absent or limited speech, and in some cases hand stereotypies and apraxia [Mari et al., 2005; Mirzaa et al., 2013].

Only approximately 20 male patients with pathogenic CDKL5 variants have been reported [Akamine et al., 2018]. Generally, the phenotypic profile is more significant in affected males, characterized by more severe seizures and infantile spasms, severe global developmental delay, and cortical visual impairment [Mirzaa et al., 2013]. Most pathogenic CDKL5 variants are reported to have occurred de novo [Akamine et al., 2018]. A single case of a male with intractable epilepsy, developmental delay, and autistic features with a missense CDKL5 variant inherited from an unaffected mother has also been described (Wong \& Kwong, 2015).

Here, we present a maternally inherited frameshift CDKL5 variant in a male with intellectual disability and late-onset generalized epilepsy, expanding the known spectrum of CDKL5-related disorder in males.

\section{CLINICAL REPORT}

The proband (III:1 in Figure 1a) is a boy born five days post-term by Caesarean section following an unremarkable pregnancy. He sat independently at 8 months, crawled at 9 months, and walked by 15 months of age. Concerns about his development were first raised at 3 years of age when he started attending nursery school. 
At 8 years of age he was referred to the Clinical Genetics department with severe developmental delay, severe intellectual disability, and autism spectrum disorder. He had limited speech with approximately 20 words and was unable to form sentences. He needed support with toileting, washing, dressing, and feeding. He picked at the skin on his fingers. He had sleep disturbances and would sleep only four to six hours a night with melatonin. There were no concerns regarding his hearing or eyesight and no history of seizures.

On examination, he had bilateral inverted nipples, but no other dysmorphic features or physical anomalies were noted. His weight was on the $98^{\text {th }}$ centile; height on the $75^{\text {th }}$ centile; and his occipital frontal circumference (OFC) was between the $91^{\text {st }}-98^{\text {th }}$ centile. He was noted to have poor eye contact in clinic, was unable to respond to simple commands, and grunted and shouted during examination.

An array comparative genomic hybridization (array CGH) (OGT CytoSure Constitutional v3 Array (8x60k); CytoSure Interpret v3.4.3) did not identify any plausible pathogenic variants and testing for fragile X syndrome (OMIM 300624) was normal. With parental written consent, trio whole exome sequencing was then performed as part of the Deciphering Developmental Disorders (DDD) research project [Deciphering Developmental Disorders Study, 2017] which showed a maternally inherited hemizygous frameshift CDKL5 c.2809_2810insA p.(Cys937Ter) (GRCh37;X:1866854118668541T>TA) variant in exon 20 (Ensembl transcript ID: ENST00000379996.7; NM_003159; NP_003150) (Figure 1b). No other likely pathogenic variants were identified. The CDKL5 variant was confirmed by Sanger sequencing. As CDKL5 variants typically cause early epileptic encephalopathy, we performed additional segregation studies in the family and reverse phenotyping in the proband [de Goede et al., 2016].

The proband's 39-year-old mother (II:2 in Figure 1a) also carried the frameshift CDKL5 variant, and was asymptomatic with no intellectual or neurological problems. X-inactivation studies (performed using Androgen Receptor (HUMAR) and ZMYM3 (ZNF261) analysis) showed random Xinactivation in a sample derived from peripheral DNA. Variant segregation studies in the family revealed that the proband's 46-year-old maternal aunt (II:5 in Figure 1a) also carried the CDKL5 
variant. She was also asymptomatic. Two 'at risk' males (II:4 and III:8 in Figure 1a) in the family without any neurodevelopmental problems were tested and did not to carry the variant.

The proband was reviewed at 13 years and 5 months of age. He remained profoundly globally delayed. Importantly, in the interim he had three generalized tonic clonic seizures at $11,12 \frac{1}{2}$ and 13 years of age and was diagnosed with generalized epilepsy. Sleep electroencephalogram (EEG) studies identified mild slowing of background activity. He exhibited repetitive behaviours including sitting and rocking, though he presented with no hand stereotypies. He demonstrated inappropriate laughter, which was sometimes followed by crying and self-directed aggression (e.g. hand biting). There was no history suggestive of developmental regression. He remained overweight $\left(96^{\text {th }}\right.$ centile) and his OFC was between the $98^{\text {th }}-99.6^{\text {th }}$ centile.

\section{DISCUSSION}

The role of CDKL5 variants as a cause of Rett syndrome (RTT)-like phenotypes was first noted in two female patients who had de novo balanced X;autosome translocations that disrupted the function of the CDKL5 gene [Kalscheuer et al., 2003]. They presented with severe early onset infantile spasms with hypsarrhythmia and profound global developmental delay [Scala et al., 2005]. CDKL5 was subsequently proposed to account for some of the phenotypic variability observed in RTT and RTTlike patients [Weaving et al., 2004]. Although broad similarities exist between CDKL5-related disease and classical RTT, including severe neurodevelopmental impairment, intellectual disability, and motor delay [Trazzi et al., 2018], key distinctions have been noted. Hagebeuk and colleagues reported that females with pathogenic $C D K L 5$ variants do not present with developmental regression, unlike in RTT, and that seizures develop earlier in CDKL5-related disease [Hagebeuk et al., 2013]. This led Fehr et al. [2015] to argue that 'CDKL5 disorder' is a more appropriate term to describe individuals with pathogenic $C D K L 5$ variants, rather than labelling them as having a 'RTT subtype'.

At least 143 females with pathogenic CDKL5 variants have been described in the medical literature [Mangatt et al., 2016]. In contrast, only about 20 males with pathogenic CDKL5 variants have been described [Akamine et al., 2018]. Of these, the majority have been predicted to have no functional 
protein. Additionally, some males have been described to have hypomorphic missense variants or truncating variants after amino acid 781 [Elia et al., 2008; Mangatt et al., 2016]. Mirzaa and colleagues reported an affected male with an affected half-sister who both had a missense CDKL5 variant that was present in mosaic form in the mother [Mirzaa et al., 2013]. It is assumed that, similar to most $\mathrm{X}$-linked dominant conditions, males with severe $C D K L 5$ variants do not survive till birth, and only milder or mosaic variants can be compatible with life. It is not yet clear if there may be some variants that result in asymptomatic females but affected males. If such variants exist, males with these variants would likely be less severely affected than males with 'classical' CDKL5-related disorder.

Here, we report a frameshift exon 20 CDKL5 variant (Ensembl transcript ID: ENST00000379996.7) in a boy with severe global developmental delay, severe intellectual disability, autistic features and epilepsy. Although the possibility of this variant not being causal cannot be completely excluded, several lines of evidence support it being pathogenic. Firstly, the severity of the phenotype of the proband is consistent with a $C D K L 5$-related disorder. We identified a slowing of the background EEG activity, which has been previously described in other patients with CDKL5-related epileptic encephalopathy [Melani et al., 2011]. Our patient also presented with sleeping difficulties, which is common in individuals with pathogenic CDKL5 variants. Fehr and colleagues report the occurrence of this in 62/69 females and 7/8 males [Fehr et al., 2013]. Our patient exhibited some, albeit minimal, language skills. This fits with findings from one cohort where early signs of speech were acquired by 30/76 females and 2/9 males [Fehr et al., 2013].

Secondly, the variant was detected in two unaffected female relatives of the proband and was absent from two 'at risk' unaffected males. Asymptomatic female carriers of pathogenic missense CDKL5 variants have been previously reported [Wong \& Kwong, 2015].

Thirdly, the variant in our patient is located in exon 20 of CDKL5 (Ensembl transcript ID: ENST00000379996.7) which, although distant from the location of most disease-causing variants, is still likely to be pathogenic. Bertani and colleagues suggested that because the $\mathrm{C}$-terminus region has 
regulatory functions, premature truncation of this region can lead to a neurological phenotype [Bertani et al., 2006]. From their comparison of CDKL5 proteins in other mammals, Intusoma and colleagues proposed that variants after the $938^{\text {th }}$ amino acid are less likely to be disease causing [Intusoma et al., 2011]. Moreover, no loss-of-function variants before p.Arg952 have been described in the general population (Exome Aggregation Consortium, 2016). The variant in our patient is predicted to terminate the protein just before the $938^{\text {th }}$ amino acid.

The age of presentation of seizures was much later in our patient than usually reported, but interestingly, another male with a de novo c.1649G>A; p.R550Q CDKL5 variant and a milder phenotype has been reported [Wong \& Kwong, 2015]. Of note, there are nine protein coding transcripts in the CDKL5 gene, only two of which include exon 20 [Zerbino et al., 2018]. Although NM_003159 is considered to be a minor CDKL5 isoform, it is expressed in the fetal brain [Williamson et al., 2012; Diebold et al., 2014]. There are, however, a number of transcripts which would not be impacted by this variant, perhaps contributing to the late seizure onset. An additional explanation could be that, given the location of this variant in exon 20 of CDKL5 transcript ENST00000379996.7, the transcript may escape nonsense-mediated decay [He \& Jacobson, 2015]. Furthermore, there is evidence to suggest that $C D K L 5$ variants located towards the C-terminus are less deleterious [Intusoma et al., 2011; Williamson et al., 2012; Diebold et al., 2014; Hector et al., 2017]. For example, Psoni and colleagues presented a female with a de novo CDKL5 c. $2908 \mathrm{C}>\mathrm{T}$ (p.Arg970X) variant towards the C-terminus of the protein without a prominent seizure disorder [Psoni et al., 2010]. An alternative disease mechanism for C-terminus truncating CDKL5 variants has been proposed via accumulation of the protein in the nucleus. Interestingly, the final three exons corresponding to transcript ENST00000379996.7 are primate specific [Diebold et al., 2014], suggesting that these exons may be less critical for gene function.

In summary, we report a novel CDKL5 variant that adds to both the variability of the documented phenotypic profile and to the debate around the role of $\mathrm{C}$-terminus variants in CDKL5-related disease. We show that $C D K L 5$-related disease can be inherited in an X-linked recessive pattern, in addition to the X-linked dominant inheritance characteristic of this disorder. 


\section{ACKNOWLEDGEMENTS}

We would like to acknowledge the Manchester Centre for Genomic Medicine laboratory Rare Disease Service for Sanger confirmation of the variant, and the Wessex Regional Genetics laboratory for performing the $\mathrm{X}$-inactivation studies. We are thankful to all individuals for participating in the study. The DDD study presents independent research commissioned by the Health Innovation Challenge Fund [grant number HICF-1009-003], a parallel funding partnership between Wellcome and the Department of Health, and the Wellcome Sanger Institute [grant number WT098051]. The views expressed in this publication are those of the author(s) and not necessarily those of Wellcome or the Department of Health. The study has UK Research Ethics Committee approval (10/H0305/83, granted by the Cambridge South REC, and GEN/284/12 granted by the Republic of Ireland REC). The research team acknowledges the support of the National Institute for Health Research, through the Comprehensive Clinical Research Network.

\section{REFERENCES}

Akamine S, Ishizaki Y, Sakai Y, Torisu H, Fukai R, Miyake C, Ohkubo K, Koga H, Sanefuji M, Sakata A, Kimura M, Yamaguchi S, Sakamoto O, Hara T, Saitsu H, Matsumoto N, Ohga S. 2018. A male case with CDKL5-associated encephalopathy manifesting transient methylmalonic acidemia. Eur J Med Genet [In press].

Allou L, Julia S, Amsallem D, El Chehadeh S, Lambert L, Thevenon J. Duffourd Y, Saunier A, Bouquet P, Pere S, Moustaïne A, Ruaud L, Roth V, Jonveaux P, Philippe C. 2017. Rett-like phenotypes: expanding the genetic heterogeneity to the KCNA2 gene and first familial case of CDKL5-related disease. Clin Genet 91:431-440.

Archer H, Evans J, Edwards S, Colley J, Newbury-Ecob R, O’Callaghan F, Huyton M, O'Regan M, Tolmie J, Sampson J, Clarke A, Osborne, J. 2006. CDKL5 mutations cause infantile spasms, early onset seizures, and severe mental retardation in female patients. J Med Genet 43:729-734. 
Bertani I, Rusconi L, Bolognese F, Forlani G, Conca B, De Monte L, Badaracco G, Landsberger N Kilstrup-Nielsen C. 2006. Functional consequences of mutations in CDKL5, an X-linked gene involved in infantile spasms and mental retardation. J Biol Chem 281:48-56.

Deciphering Developmental Disorders Study. 2017. Prevalence and architecture of de novo mutations in developmental disorders. Nature 542:433-438.

de Goede C, Yue W, Yan G, Ariyaratnam S, Chandler K, Downes L, Khan N, Mohan M, Lowe M, Banka S. 2016. Role of reverse phenotyping in interpretation of next generation sequencing data and a review of INPP5E related disorders. Eur J Paediatr Neurol 20:286-295.

Diebold B, Delépine C, Gataullina S, Delahaye A, Nectoux J, Bienvenu T. 2014. Mutations in the Cterminus of CDKL5: proceed with caution. Eur J Hum Genet 22:270-272.

Elia M, Falco M, Ferri R, Spalletta A, Bottitta M, Calabrese G, Carotenuto M, Musumeci SA, Lo Giudice M, Fichera M. 2008. CDKL5 mutations in boys with severe encephalopathy and early-onset intractable epilepsy. Neurology 71:997-999.

Evans J, Archer H, Colley J, Ravn K, Bieber-Nielsen J, Kerr A, Williams E, Christodoulou J, Gécz J, Jardine P, Wright M, Pilz D, Lazarou L, Cooper D, Sampson J, Butler R, Whatley S, Clarke A. 2005. Early onset seizures and Rett-like features associated with mutations in CDKL5. Eur J Hum Genet 13:1113-1120.

Exome Aggregation Consortium. 2016. Analysis of protein-coding genetic variation in 60,706 humans. Nature 536:285-291.

Fehr S, Leonard H, Gladys H, Williams S, de Klerk N, Forbes D, Christodoulou J, Downs J. 2015. There is variability in the attainment of developmental milestones in the CDKL5 disorder. J Neurodev Disord 7(2):1-13.

Fehr S, Wilson M, Downs J, Williams S, Murgia A, Sartori S, Vecchi M, Ho G, Polli R, Psoni S, Bao X, de Klerk N, Leonard H, Christodoulou J. 2013. The CDKL5 disorder is an independent clinical entity associated with early-onset encephalopathy. Eur J Hum Genet 21:266-273. 
Hagebeuk E, Van Den Bossche R, De Weerd A. 2013. Respiratory and sleep disorders in female children with atypical Rett syndrome caused by mutations in the CDKL5 gene. Dev Med Child Neurol 55:480-484.

He F, Jacobson A. 2015. Nonsense-Mediated mRNA Decay: Degradation of Defective Transcripts Is Only Part of the Story. Annu Rev Geneti 49:339-366.

Hector R, Kalscheuer V, Hennig F, Leonard H, Downs J, Clarke A, Benke T, Armstrong J, Pineda M, Bailey M, Cobb S. 2017. CDKL5 variants: Improving our understanding of a rare neurologic disorder. Neurol Genet 3(e200):1-10.

Intusoma U, Hayeeduereh $\mathrm{F}$, Plong-On $\mathrm{O}$, Sripo $\mathrm{T}$, Vasiknanonte $\mathrm{P}$, Janjindamai $\mathrm{S}$, Lusawat A, Thammongkol S, Visudtibhan A, Limprasert P. 2011. Mutation screening of the CDKL5 gene in cryptogenic infantile intractable epilepsy and review of clinical sensitivity. Eur J Paediatr Neurol 15:432438.

Kalscheuer V, Donnelly A, Hollway G, Schwinger E, Kübart S, Menzel C, Menzel C, Hoeltzenbein M, Tommerup N, Eyre H, Harbord M, Haan E, Sutherland GR, Ropers H, Gécz J. 2003. Disruption of the serine/threonine kinase 9 gene causes severe X-linked infantile spasms and mental retardation. Am J Hum Genet 72:1401-1411.

Mangatt M, Wong K, Anderson B, Epstein A, Hodgetts S, Leonard H, Downs J. 2016. Prevalence and onset of comorbidities in the CDKL5 disorder differ from Rett syndrome. Orphanet J Rare Dis 11(39): 117.

Mari F, Azimonti S, Berani I, Bolognese F, Colombo E, Caselli R, Scala E, Longo I, Grosso S, Pescucci C, Ariani F, Hayek G, Balestri P, Bergo A, Badaracco G, Zappella M, Broccoli V, Renieri A, KilstrupNielsen C, Landsberger N. 2005. CDKL5 belongs to the same molecular pathway of MeCP2 and it is responsible for the early-onset seizure variant of Rett syndrome. Hum Molecular Genet 14:1935-1946.

Melani F, Mei D, Pisano T, Savasta S, Franzoni E, Ferrari A, Marini C, Guerrini R. 2011. CDKL5 generelated epileptic encephalopathy: electroclinical findings in the first year of life. Dev Med Child Neurol $53: 354-360$. 
Mirzaa G, Paciorkowski A, Marsh E, Berry-Kravis E, Medne L, Alkhateeb A, Grix A, Wirrell E, Powell B, Nickels K, Burton B, Paras A, Kim K, Chung W, Dobyns W, Das S. 2013. CDKL5 and ARX mutations in males with early-onset epilepsy. Pediatr Neurol 48:367-377.

Psoni S, Willems P, Kanavakis E, Mavrou A, Frissyra H, Traeger-Synodinos J, Sofokleous C, Makrythanassis P, Kitsiou-Tzeli S. 2010. A novel p.Arg970X mutation in the last exon of the CDKL5 gene resulting in late-onset seizure disorder. Eur J Paediatr Neurol 14:188-191.

Scala E, Ariani F, Mari F, Caselli R, Pescucci C, Longo I, Meloni I, Giachino D, Bruttini M, Hayek G, Zappella M, Renieri A. 2004. CDKL5/STK9 is mutated in Rett syndrome variant with infantile spasms. J Med Genet 42:103-107.

Tao J, Van Esch H, Hagedorn-Greiwe M, Hoffmann K, Moser B, Raynaud M, Sperner J, Fryns J, Schwinger E, Gécz J, Ropers H, Kalscheuer V. 2004. Mutations in the X-linked cyclin-dependent kinase-like 5 (CDKL5/STK9) gene are associated with severe neurodevelopmental retardation. Am J Hum Genet 75:1149-1154.

Trazzi S, De Franceschi M, Fuchs C, Bastianini S, Viggiano R, Lupori L, Mazziotti R, Medici G, Lo Martire V, Ren E, Rimondini R, Zoccoli G, Bartesaghi R, Pizzorusso T, Ciani E. 2018. CDKL5 protein substitution therapy rescues neurological phenotypes of a mouse model of CDKL5 disorder. Hum Mol Genet 27:1572-1592.

Weaving L, Christodoulou J, Williamson S, Friend K, McKenzie O, Archer H, Evans J, Clarke A, Pelka G, Tam P, Watson C, Lahooti H, Ellaway C, Bennetts B, Leonard H, Gécz J. 2004. Mutations of CDKL5 cause a severe neurodevelopmental disorder with infantile spasms and mental retardation. Am J Hum Genet 75:1079-1093.

Williamson S, Giudici L, Kilstrup-Nielsen C, Gold W, Pelka G, Tam P, Grimm A, Prodi D, Landsberger N, Christodoulou J. 2012. A novel transcript of cyclin-dependent kinase-like 5 (CDKL5) has an alternative C-terminus and is the predominant transcript in brain. Hum Genet 131:187-200.

Wong V, Kwong A. 2015. CDKL5 variant in a boy with infantile epileptic encephalopathy: Case report. Brain Dev 37:446-448. 
Zerbino D, Achuthan P, Akanni W, Amode M, Barrell D, Bhai J, Billis K, Cummins C, Gall A, Giron C, Gil L, Gordon L, Haggerty L, Haskell E, Hourlier T, Izuogu O, Janacek S, Juettemann T, To J, Laird M, Lavidas I, Liu Z, Loveland J, Maurel T, McLaren W, Moore B, Mudge J, Murphy D, Newman V, Nuhn M, Ogeh D, Ong C, Parker A, Patricio M, Riat H, Schuilenburg H, Sheppard D, Sparrow H, Taylor K, Thormann A, Vullo A, Walts B, Zadissa A, Frankish A, Hunt S, Kostadima M, Langridge N, Martin F, Muffato M, Perry E, Ruffier M, Staines D, Trevanion S, Aken B, Cunningham F, Yates A, Flicek P. 2018. Ensembl 2018. Nucleic Acids Res 46(D1):754-761.

\section{FIGURE LEGENDS}

\section{Figure 1: An inherited frameshift variant in CDKL5 exon 20}

(A) Family pedigree: Standard symbols have been used to draw the pedigree.

(B) Exon-intron structure of the CDKL5 gene demonstrating the location of the variant in exon 20 of the transcript ENST00000379996.7 and transcript comparison. Image drawn using Golden Helix VarSeq software; Details of CDKL5 c.2809_2810insA (ENST00000379996.7) p.(Cys937Ter) (GRCh37;X:18668541-18668541T>TA) variant.

(C) Chromatogram from the Sanger confirmation of the CDKL5 c.2809_2810insA (ENST00000379996.7) p.(Cys937Ter) (GRCh37;X:18668541-18668541T>TA) variant. 